\title{
Produtividade e Qualidade de Sementes de Soja em Função de Estádios de DESSECAÇÃo E HERBICIdAS ${ }^{1}$
}

\author{
Productivity and Quality of Soybean Seeds in Function of Desiccation Stages and \\ Herbicides
}

\author{
GUIMARÃES, V.F. ${ }^{2}$, HOLLMANN, M.J. ${ }^{3}$, FIOREZE, S.L. ${ }^{4}$, ECHER, M.M. ${ }^{5}$, \\ RODRIGUES-COSTA, A.C.P. ${ }^{6}$ e ANDREOTTI, M. ${ }^{7}$
}

\begin{abstract}
RESUMO - O objetivo deste trabalho foi avaliar a melhor época de aplicação de dessecantes, de forma a permitir antecipação da colheita sem prejudicar a produtividade e qualidade de sementes de soja. O delineamento experimental foi de blocos ao acaso em esquema fatorial $(3 \times 3)+1$, com quatro repetições. Um dos fatores foi constituído pelos herbicidas dessecantes paraquat, glufosinato de amônio e glyphosate, nas doses de 400, 400 e 960 g i.a. ha ${ }^{-1}$, respectivamente. Outro fator constituiu-se de três estádios de aplicação dos herbicidas, via pulverização (R6, R7.2 e R8.1). Avaliaram-se a antecipação da colheita, massa de 100 sementes, produtividade, germinação e vigor das sementes. A utilização de herbicidas, aliada aos estádios fenológicos de aplicação, permitiu antecipar a colheita de um a seis dias. A dessecação de plantas de soja em pré-colheita com os herbicidas nos diferentes estádios fenológicos não afetou a produtividade. O herbicida glufosinato de amônio reduziu a germinação de sementes de soja quando aplicado no estádio R6. O herbicida glyphosate reduziu o vigor das sementes de soja quando aplicado nos estádios R6 e R7.2. O herbicida paraquat promoveu os melhores indices de germinação e vigor de sementes de soja quando utilizado nos estádios R6 e R7.2.
\end{abstract}

Palavras-chave: Glycine max, antecipação de colheita, germinação, vigor.

\begin{abstract}
The objective of this work was to evaluate the best time to apply desiccants to allow earlier harvesting without compromising seed quality and yield of soybean plants. The experiment was arranged in a randomized block design in a factorial scheme (3x3) + 1, with four replications. One factor was composed of the desiccant herbicides paraquat, glu fosinate ammonium, and glyphosate at doses of 400, 400, and $960 \mathrm{~g}$ a.i. ha-1, respectively. The other factor was constituted of three phenological herbicide application stages (R6, R7.2, and R8.1). Harvest anticipation, mass of 100 seeds, yield, germination, and seed vigor were evaluated. The use of herbicides combined with the phenological application stages allowed to anticipate harvest from one to six days. Desiccation of the soybean plants in pre-harvest using herbicides at different phenological stages did not affect yield. Glufosinate ammonium reduced the germination of soybean seeds when applied at R6. Glyphosate reduced the vigor of soybean seeds when applied at R6 and R7.2.
\end{abstract}

Keywords: Glycine max, harvest anticipation, germination, vigor.

1 Recebido para publicação em 18.5.2011 e aprovado em 22.5.2012.

2 Professor Associado, Centro de Ciências Agrárias, Universidade Estadual do Oeste do Paraná - CCA/UNIOESTE, Campus de Marechal Cândido Rondon, Caixa Postal 91, 85960-000 Marechal Cândido Rondon-PR, <vandeirfg@yahoo.com.br>; ${ }^{3}$ Engo-Agro ${ }^{\text {. }}$; ${ }^{4}$ Doutorando, FCA/UNESP, Botucatu-SP, ${ }^{5}$ Professora Adjunta, CCA/UNIOESTE, Marechal Cândido Rondon-PR; ${ }^{6}$ Bolsista Pós-Doutorado, CCA/UNIOESTE, Marechal Cândido Rondon-PR; ${ }^{7}$ Professor Adjunto, Dep. de Fitossanidade, Engenharia Rural e Solos, FEIS/UNESP, Ilha Solteira-SP.

Planta Daninha, Viçosa-MG, v. 30, n. 3, p. 567-573, 2012 


\section{INTRODUÇÃO}

Entre os fatores que afetam o potencial fisiológico e sanitário das sementes de soja, destacam-se o momento da colheita e as condições do ambiente durante o período em que as sementes permanecem no campo. A antecipação da colheita reduz os riscos de deterioração no campo e permite a obtenção de sementes de qualidade superior, colhidas mais próximo da maturidade (Terasawa et al., 2009).

O controle de qualidade de sementes de soja é de fundamental importância na sua cadeia produtiva, caracterizando a colheita como importante etapa do processo (Embrapa, 2002).

Na produção de sementes, a antecipação da colheita permite a obtenção de sementes de melhor qualidade fisiológica e sanitária, por evitar danos que possam ocorrer no campo devido às condições climáticas adversas, como chuvas na pré-colheita, bem como ataques de pragas e microrganismos (Veiga et al., 2007).

Braccini et al. (2003) compararam sementes de soja colhidas em época normal (estádio R8) e após 30 dias de retardamento da colheita e concluíram que a máxima qualidade da semente é obtida por ocasião da maturidade fisiológica, pois a permanência da semente no campo após esta fase acelera o processo de deterioração.

Para Inoue et al. (2003), a dessecação da soja com a finalidade de antecipar a colheita é uma alternativa empregada para minimizar a deterioração da qualidade das sementes. Por ser realizada com a maioria das sementes maduras, promove a secagem rápida das plantas e o aumento da uniformidade de maturação, o que facilita a colheita com menor teor de impurezas e sementes de melhor qualidade, além de reduzir as perdas e o custo de secagem.

Conforme recomendações técnicas da Embrapa (2002), a dessecação da soja pode ser efetuada somente em áreas de produção de grãos, com o objetivo de controlar plantas daninhas ou uniformizar as plantas com problemas de haste verde e retenção foliar. Roman et al. (2001) preconizam a dessecação como uma técnica para antecipar a colheita, com a vantagem de uniformizá-la e facilitá-la, reduzir perdas, impurezas e melhorar a qualidade dos grãos colhidos.
Santos et al. (2000) concluíram que não houve interferência de dessecantes na produtividade e na germinação de sementes de soja. Esses autores relatam que a prática pode ser adotada, pois em condições climáticas adversas poderá evitar a deterioração em campo, uma vez que antecipou a colheita em seis dias. Para Lacerda et al. (2001), é possivel antecipar a colheita sem alterar a produtividade, dependendo das condições climáticas. Contudo, quando ocorrem condições favoráveis à sua maturação (alta temperatura e baixa umidade), estes autores não recomendam dessecar soja com fins de antecipar a colheita.

Nakashima et al. (2000) obtiveram sementes com elevada qualidade fisiológica, sem redução significativa da produtividade, com aplicações do herbicida paraquat, no estádio R6.5, antecipando a colheita dos cultivares Savana e Doko em 11 e 7 dias, respectivamente.

Avaliando características fisiológicas, bioquímicas e sanitárias de sementes de soja colhidas após dessecação com quatro dessecantes, Lacerda (2003) observou que a germinação de sementes provenientes de plantas dessecadas com glufosinato de amônio foi menor, quando comparada com a dessecação feita com paraquat, diquat e suas misturas.

Alguns aspectos fundamentais devem ser considerados com relação à utilização de dessecantes na pré-colheita da soja, como a escolha do herbicida e a época ideal de sua aplicação, para que não haja prejuízo na produtividade e, principalmente, na qualidade fisiológica das sementes. Em razão das poucas informações na literatura, torna-se fundamental a realização de estudos que possam auxiliar nas tomadas de decisão de manejo da cultura.

O objetivo foi avaliar a melhor época de aplicação de dessecantes, de forma a permitir a máxima antecipação da colheita sem prejudicar a produtividade e qualidade de sementes de soja.

\section{MATERIAL E MÉTODOS}

O presente trabalho foi conduzido em campo. As coordenadas geográficas da área são: latitude de $24^{\circ} 29^{\prime} 70^{\prime \prime} \mathrm{S}$ e longitude de $54^{\circ} 05^{\prime} 38^{\prime \prime} \mathrm{WGr}$, com altitude média de $350 \mathrm{~m}$. 
O solo é um Latossolo Vermelho Eutroférrico (Embrapa, 1999).

O cultivar de soja utilizado foi o BRS 184, semeado em sistema de plantio convencional no dia 20/10/2004, com população final de 310.000 plantas ha ${ }^{-1}$. A adubação utilizada foi de $250 \mathrm{~kg} \mathrm{ha}^{-1}$ do adubo formulado 2-20-20 (N-P-K). A lavoura foi conduzida livre de plantas daninhas, com aplicação de herbicidas e complemento com capina manual. No estádio R5.1 da cultura da soja, realizou-se a aplicação de fungicida à base de tetraconazole.

As parcelas experimentais foram constituídas de sete linhas da cultura, espaçadas de $0,45 \mathrm{~m}$ entre si, por $6 \mathrm{~m}$ de comprimento, totalizando $18,9 \mathrm{~m}^{2}$. Como parcela útil, utilizaramse as três linhas centrais, desprezando-se um metro de cada extremidade, totalizando $5,4 \mathrm{~m}^{2}$.

O delineamento experimental foi de blocos ao acaso em esquema fatorial $(3 \times 3)+1$, sendo três herbicidas dessecantes aplicados nos estádios fenológicos R6, R7.2, R8.1, mais uma testemunha sem aplicação de dessecante, com quatro repetições, totalizando 40 parcelas experimentais. Os herbicidas dessecantes utilizados foram glyphosate (960 g i.a. ha-1), glufosinato de amônio + Hoefix (espalhante adesivo) $\left(400+195,3\right.$ g i.a. ha $\left.{ }^{-1}\right)$ e paraquat (400 g i.a. ha ${ }^{-1}$ ), sendo o primeiro herbicida com ação sistêmica e os demais com ação de contato.

Os herbicidas dessecantes foram aplicados com um pulverizador costal pressurizado a $\mathrm{CO}_{2}$. A barra de aplicação estava equipada com seis pontas TT 110.03, calibradas para um volume de calda de $200 \mathrm{~L} \mathrm{ha}^{-1}$. As plantas foram colhidas quando estavam visualmente secas. A colheita foi realizada em épocas diferentes, conforme descrito na Tabela 1. Após a colheita, foram avaliadas as variáveis relativas a componentes da produção, teor de água das sementes na colheita, massa de sementes por parcela e massa de 100 sementes. A produtividade foi calculada e expressa em $\mathrm{kg} \mathrm{ha}^{-1}$, após correção do teor de água das sementes para $13 \%$.

Para avaliação da qualidade fisiológica das sementes em laboratório, foram utilizados testes de germinação e vigor. O teste de germinação foi realizado pelo método tradicional descrito nas Regras para Análise de Sementes
(Brasil, 2009), com algumas modificações. A montagem do teste foi feita com 400 sementes por tratamento, sendo oito rolos de 50 sementes cada. As sementes foram colocadas em rolos de papel umedecidos com água na proporção de 2,5 vezes o peso do papel seco, os quais, em seguida, foram levados ao germinador a uma temperatura de $25{ }^{\circ} \mathrm{C}$, com $100 \%$ de umidade relativa do ar, por um período de oito dias. As avaliações foram realizadas no quinto e oitavo dias, quando foram computadas as plântulas normais e anormais e as sementes deterioradas, sendo os resultados expressos em porcentagem.

Utilizou-se como teste de vigor o envelhecimento acelerado. Para isso, 400 sementes de cada tratamento foram acondicionadas em caixas do tipo gerbox, sobre uma tela de cobre. Em cada caixa, foram adicionados $400 \mathrm{~mL}$ de água destilada que não entrou em contato com a semente, formando minicâmaras úmidas. As caixas gerbox adaptadas foram levadas para a câmara de envelhecimento acelerado, onde permaneceram por 48 horas com umidade relativa do ar entre 90 e $100 \%$ e temperatura entre 40 e $45^{\circ} \mathrm{C}$. Depois de retiradas da câmara, as sementes foram colocadas para germinar e avaliadas como no teste de germinação, anteriormente descrito.

Os resultados obtidos para os componentes da produção e produtividade, bem como para os testes de qualidade das sementes, foram submetidos à análise de variância, e as médias obtidas, comparadas pelo teste de Tukey

Tabela 1 - Dados de estádio de dessecação, datas da colheita, dias após a dessecação e dias após o plantio em relação aos diferentes herbicidas avaliados na soja, cultivar BRS-184

\begin{tabular}{|l|c|c|c|c|}
\hline \multicolumn{1}{|c|}{ Herbicida } & $\begin{array}{c}\text { Estádio de } \\
\text { dessecação }\end{array}$ & $\begin{array}{c}\text { Data da } \\
\text { colheita }\end{array}$ & $\begin{array}{c}\text { Dias após } \\
\text { dessecação }\end{array}$ & $\begin{array}{c}\text { Dias após } \\
\text { plantio }\end{array}$ \\
\hline Glyphosate & R6 & $16 / 02$ & 9 & 119 \\
\hline Glyphosate & R7.2 & $18 / 02$ & 7 & 121 \\
\hline Glyphosate & R8.1 & $21 / 02$ & 6 & 124 \\
\hline G. de amônio & R6 & $18 / 02$ & 11 & 121 \\
\hline G. de amônio & R7.2 & $18 / 02$ & 7 & 121 \\
\hline G. de amônio & R8.1 & $21 / 02$ & 6 & 124 \\
\hline Paraquat & R6 & $16 / 02$ & 9 & 119 \\
\hline Paraquat & R7.2 & $16 / 02$ & 5 & 119 \\
\hline Paraquat & R8.1 & $19 / 02$ & 4 & 122 \\
\hline Testemunha & --- & $22 / 02$ & --- & 125 \\
\hline
\end{tabular}

Planta Daninha, Viçosa-MG, v. 30, n. 3, p. 567-573, 2012 
a $5 \%$ de probabilidade. A testemunha foi comparada individualmente com cada tratamento, por meio do teste de Dunnett a 5\% de probabilidade.

\section{RESULTADOS E DISCUSSÃO}

A massa de 100 sementes foi influenciada pelo estádio de aplicação dos herbicidas (Tabela 2). A dessecação realizada no estádio R6 proporcionou acréscimos na massa de 100 sementes, enquanto na dessecação realizada no estádio R7.2 o resultado foi inferior ao da testemunha, independentemente do herbicida utilizado. Pelúzio et al. (2008) não verificaram diferenças no peso de 100 sementes entre épocas de dessecação da cultura da soja.

Quanto à variável produtividade, não houve diferenças entre as épocas de dessecação e produtos dessecantes quando comparadas entre estes e a testemunha, sem aplicação de herbicida dessecante (Tabelas 2 e 3). As produtividades correspondentes aos diferentes tratamentos apresentaram-se boas, pois os valores superaram $3.000 \mathrm{~kg} \mathrm{ha}^{-1}$. Esses resultados corroboram os encontrados por Daltro et al. (2010), que constataram não haver diferenças entre produtos dessecantes e épocas de aplicação na produtividade final da soja.

Lacerda et al. (2001) observaram que herbicidas dessecantes aplicados nos estádios em que já ocorreu a maturação físiológica das sementes não interferiram na produtividade da cultura da soja. Por outro lado, mesmo nas parcelas que foram dessecadas no estádio R6 (antes da maturação fisiológica) não foram observadas perdas na produtividade.

De acordo com a Embrapa (2003), a aplicação de dessecantes antes do estádio R7 provoca perdas na produtividade, o que não foi constatado neste estudo. A ausência de significância entre os tratamentos deve-se, provavelmente, ao déficit hídrico que se iniciou no final da fase reprodutiva da cultura, resultando no encurtamento no período de enchimento de grãos para todos os tratamentos, o que antecipou a maturação fisiológica das sementes, cessando a translocação de solutos orgânicos precocemente.
Tabela 2 - Massa de 100 sementes e produtividade da soja, cultivar BR 184, em função dos estádios de dessecação

\begin{tabular}{|l|c|c|}
\hline $\begin{array}{c}\text { Estádio de } \\
\text { dessecação }\end{array}$ & $\begin{array}{c}\text { Massa de 100 } \\
\text { sementes }(\mathrm{g})\end{array}$ & $\begin{array}{c}\text { Produtividade } \\
\left(\mathrm{kg} \mathrm{ha}^{-1}\right)\end{array}$ \\
\hline R6 & $13,7 \mathrm{a}$ & $3287,6 \mathrm{a}$ \\
\hline R7.2 & $12,9 * \mathrm{~b}$ & $3226,1 \mathrm{a}$ \\
\hline R8.1 & $13,4 \mathrm{ab}$ & $3091,9 \mathrm{a}$ \\
\hline Testemunha & 13,5 & 3195,1 \\
\hline DMS (Dunnett) & 0,61 & 259,17 \\
\hline CV (\%) & 4,52 & 7,96 \\
\hline
\end{tabular}

Médias seguidas da mesma letra, na coluna, não diferem estatisticamente pelo teste de Tukey $(\mathrm{p}<0,05)$. * Difere estatisticamente da testemunha pelo teste de Dunnett $(\mathrm{p}<0,05)$.

Tabela 3 - Massa de 100 sementes e produtividade da soja, cultivar BR 184, em função dos herbicidas dessecantes

\begin{tabular}{|l|c|c|}
\hline \multicolumn{1}{|c|}{ Herbicida } & $\begin{array}{c}\text { Massa de 100 } \\
\text { sementes }(\mathrm{g})\end{array}$ & $\begin{array}{c}\text { Produtividade } \\
\left(\mathrm{kg} \mathrm{ha}^{-1}\right)\end{array}$ \\
\hline Glyphosate & $13,5 \mathrm{a}$ & $3287,6 \mathrm{a}$ \\
\hline Glufosinato de amônio & $13,3 \mathrm{a}$ & $3203,6 \mathrm{a}$ \\
\hline Paraquat & $13,1 \mathrm{a}$ & $3114,4 \mathrm{a}$ \\
\hline Testemunha & 13,6 & 3195,1 \\
\hline DMS (Dunnett) & 0,61 & 259,17 \\
\hline CV (\%) & 4,52 & 7,96 \\
\hline
\end{tabular}

Médias seguidas da mesma letra, na coluna, não diferem estatisticamente pelo teste de Tukey $(\mathrm{p}<0,05)$. As médias dos tratamentos não diferiram estatisticamente da testemunha pelo teste de Dunnett $(\mathrm{p}<0,05)$.

Observa-se que as sementes provenientes de plantas de soja dessecadas no estádio R6 com os herbicidas glyphosate e glufosinato de amônio apresentaram decréscimo na germinação, quando comparados com o herbicida paraquat utilizado na mesma época (Tabela 4). A dessecação feita com o herbicida glufosinato de amônio no estádio R6 proporcionou porcentagem de germinação inferior $(12,27 \%)$ à da testemunha. Lacerda (2003) também observou menor germinação de sementes provenientes de plantas dessecadas com glufosinato de amônio, quando comparado a sementes de plantas dessecadas com paraquat ou diquat no estádio entre R6 e R7.

Não foram constatadas diferenças significativas na porcentagem de germinação entre os fatores herbicidas dessecantes utilizados nos estádios R7.2 e R8.1. Contudo, nos estádios R6 e R7.2, a dessecação com paraquat resultou 
em sementes com porcentagem de germinação superior à da testemunha em 5,7 e 7,6\%, respectivamente. Durigan (1980), aо avaliar a aplicação de paraquat em alguns cultivares de soja, concluiu que ela não prejudicou a qualidade das sementes. Nakashima et al. (2000) obtiveram resultados semelhantes utilizando paraquat no estádio R6.5, com sementes de elevada qualidade fisiológica, sem redução significativa na produção.

Observa-se que as plantas dessecadas no estádio R6, com os herbicidas glyphosate e glufosinato de amônio, proporcionaram maior porcentagem de plântulas anormais, quando comparados com paraquat utilizado na mesma época (Tabela 5). O glufosinato de amônio, utilizado no estádio R6, resultou em maior porcentagem de plântulas anormais, quando comparado com a testemunha sem dessecação.
Esse fato pode ter ocorrido em razão de o paraquat ser um herbicida de contato; a morte dos tecidos das plantas, após sua aplicação, ocorre de maneira rápida, limitando, dessa forma, a translocação do produto ou dos fotossintatos para o interior das sementes (Ratnayake \& Shaw, 1992). O glufosinato de amônio, apesar de ser também um herbicida de contato, possui mais facilidade de translocação do que o paraquat (Lacerda et al., 2005) e, por esse motivo, talvez tenha havido maiores danos quando aplicado nos estádios R6 da cultura.

Sementes procedentes de plantas dessecadas com glyphosate, tanto em R6 quanto em R7.2 (Tabela 6), apresentaram sementes menos vigorosas em relação aos demais tratamentos, que não diferiram entre si, sendo esse resultado inferior ao da testemunha.

Tabela 4 - Porcentagem de germinação de sementes de soja, cultivar BR 184, em função dos herbicidas e estádios de dessecação

\begin{tabular}{|c|c|c|c|c|}
\hline \multirow{2}{*}{ Herbicida } & \multicolumn{3}{|c|}{ Estádio de dessecação } & \multirow{2}{*}{ Média } \\
\hline & R6 & R7.2 & R8.1 & \\
\hline Glyphosate & $87,8 \mathrm{bA}$ & $93,0 \mathrm{aA}$ & $86,5 \mathrm{aA}$ & 89,1 \\
\hline Glufosinato de amônio & $78,3 * \mathrm{cB}$ & $93,5 \mathrm{aA}$ & $93,0 \mathrm{aA}$ & 88,2 \\
\hline Paraquat & $94,3 * \mathrm{aAB}$ & $96,0 * a A$ & $91,5 \mathrm{aB}$ & 93,9 \\
\hline Média & 86,8 & 94,2 & 90,3 & \\
\hline Testemunha & \multicolumn{4}{|c|}{89,25} \\
\hline DMS (Dunnett) & \multicolumn{4}{|c|}{4,65} \\
\hline CV $(\%)$ & \multicolumn{4}{|c|}{7,56} \\
\hline
\end{tabular}

Médias seguidas da mesma letra, minúscula na coluna e maiúscula na linha, não diferem estatisticamente pelo teste de Tukey $(\mathrm{p}<0,05)$

* Difere estatisticamente da testemunha pelo teste de Dunnett $(\mathrm{p}<0,05)$.

Tabela 5 - Porcentagem de plântulas anormais de soja, cultivar BR 184, no teste de germinação, em função dos herbicidas e estádios de dessecação

\begin{tabular}{|l|c|c|c|c|}
\hline \multirow{2}{*}{ Herbicida } & \multicolumn{3}{|c|}{ Estádio de dessecação } & \multirow{2}{*}{ Média } \\
\cline { 2 - 5 } & R6 & R7.2 & R8.1 \\
\hline Glyphosate & $8,8 \mathrm{aA}$ & $3,5 \mathrm{aA}$ & $4,0 \mathrm{aA}$ & 5,4 \\
\hline Glufosinato de amônio & $13,0 * \mathrm{aA}$ & $3,2 \mathrm{aB}$ & $4,2 \mathrm{aB}$ & 6,0 \\
\hline Paraquat & $3,0 \mathrm{bA}$ & $3,0 \mathrm{aA}$ & 3,3 & 3,4 \\
\hline Média & 8,5 & 3,2 & 6,00 & \\
\hline Testemunha & & & 5,36 & \\
\hline DMS (Dunnett) & & 58,64 & \\
\hline CV (\%) & & & \\
\hline
\end{tabular}

Médias seguidas da mesma letra, minúscula na coluna e maiúscula na linha, não diferem estatisticamente pelo teste de Tukey ( $p<0,05$ ).

* Difere estatisticamente da testemunha pelo teste de Dunnett $(\mathrm{p}<0,05)$ 
Santos et al. (2000) obtiveram resultados semelhantes, concluindo que o paraquat proporcionou maior vigor das sementes de soja que o glyphosate.

O herbicida paraquat aplicado nos estádios R6 e R7.2 e o herbicida glufosinato de amônio aplicado no estádio R7.2 proporcionaram sementes mais vigorosas que as da testemunha. Resultados semelhantes foram encontrados por Kappes et al. (2009), os quais verificaram que os lotes de sementes de soja dessecados com paraquat apresentaram melhor desempenho em testes de qualidade de sementes, em relação à testemunha.

A utilização do herbicida glyphosate resultou em aumento da porcentagem de plântulas anormais derivadas do teste de vigor em relação ao paraquat e glufosinato de amônio, aplicados no estádio R6, e à testemunha, sem dessecação (Tabela 7), o que não ocorreu quando se avaliaram plântulas anormais derivadas do teste de germinação (Tabela 5); o glufosinato de amônio proporcionou aumento significativo na porcentagem de plântulas anormais em relação ao paraquat e á testemunha, não diferindo do glyphosate no estádio R6. A aplicação do herbicida glufosinato de amônio no estádio R6 aumentou a porcentagem de plântulas anormais, quando comparado com a testemunha, e apresentou diferença significativa em relação ao paraquat aplicado na mesma época.

Os herbicidas dessecantes apresentaram diferentes respostas entre si em relação à testemunha no que diz respeito à antecipação na colheita. O paraquat utilizado na dessecação nos estádios R6 e R7.2 e o glyphosate aplicado no estádio R6 proporcionaram maior antecipação de colheita (seis dias). Resultados

Tabela 6 - Vigor de sementes de soja, cultivar BR 184, pelo teste de envelhecimento acelerado, em função dos herbicidas e estádios de dessecação

\begin{tabular}{|l|c|c|c|c|}
\hline \multirow{2}{*}{ Herbicida } & \multicolumn{3}{|c|}{ Estádio de dessecação } & \multirow{2}{*}{ Média } \\
\cline { 2 - 5 } & R6 & R7.2 & R8.1 & 64,3 \\
\hline Glyphosate & $48,3 * \mathrm{bB}$ & $69,5 * \mathrm{bA}$ & $74,8 \mathrm{aA}$ & 76,8 \\
\hline Glufosinato de amônio & $76,5 \mathrm{aA}$ & $79,3 * \mathrm{aA}$ & $75,5 \mathrm{aA}$ & 80,3 \\
\hline Paraquat & $82,2 * \mathrm{aA}$ & $83,2 * \mathrm{aA}$ & 75,2 & \\
\hline Média & 69,0 & 77,3 & 74,20 & \\
\hline Testemunha & & & 4,32 & \\
\hline DMS (Dunnett) & & & \\
\hline CV (\%) & & 8,47 & \\
\hline
\end{tabular}

Médias seguidas da mesma letra, minúscula na coluna e maiúscula na linha, não diferem estatisticamente pelo teste de Tukey ( $p<0,05)$

* Difere estatisticamente da testemunha pelo teste de Dunnett $(\mathrm{p}<0,05)$

Tabela 7 - Porcentagem de plântulas anormais de soja, cultivar BR 184, no teste de envelhecimento acelerado, em função dos herbicidas e estádios de dessecação

\begin{tabular}{|l|c|c|c|c|}
\hline \multirow{2}{*}{ Herbicida } & \multicolumn{3}{|c|}{ Estádio de dessecação } & \multirow{2}{*}{ Média } \\
\cline { 2 - 5 } & $\mathrm{R} 6$ & $\mathrm{R} 7.2$ & $\mathrm{R} 8.1$ & 20,8 \\
\hline Glyphosate & $40,5 * \mathrm{aA}$ & $10,5 \mathrm{aB}$ & $6,8 \mathrm{bB}$ & 10,5 \\
\hline Glufosinato de amônio & $13,2 * \mathrm{bA}$ & $11,5 \mathrm{aA}$ & $9,7 \mathrm{abA}$ & 7,1 \\
\hline Paraquat & $6,0 \mathrm{cA}$ & $5,5 \mathrm{aA}$ & 3,3 & \\
\hline Média & 8,5 & 3,2 & 6,00 & \\
\hline Testemunha & & & 5,36 & \\
\hline DMS (Dunnett) & & & \\
\hline CV (\%) & & 29,45 & \\
\hline
\end{tabular}

Médias seguidas da mesma letra, minúscula na coluna e maiúscula na linha, não diferem estatisticamente pelo teste de Tukey (p $<0,05$ )

* Difere estatisticamente da testemunha pelo teste de Dunnett $(\mathrm{p}<0,05)$. 
semelhantes foram obtidos por Lacerda el al. (2001), que concluíram ser possivel antecipar a colheita sem alterar a produtividade em no máximo sete dias, dependendo das condições climáticas.

Quando o glyphosate foi utilizado na dessecação no estádio R7.2, proporcionou antecipação na colheita de quatro dias, mas, quando utilizado no estádio R8.1, antecipou a colheita em apenas um dia. O glufosinato de amônio utilizado na dessecação nos estádios R6 e R7.2 antecipou a colheita em quatro dias e, no estádio R8.1, em um dia.

Diante dos resultados, conclui-se que a dessecação de plantas de soja em pré-colheita, com os herbicidas e estádios fenológicos estudados, não reduziu a produtividade. O herbicida glufosinato de amônio reduziu a germinação de sementes de soja quando aplicado no estádio R6. O glyphosate reduziu o vigor das sementes de soja quando aplicado nos estádios R6 e R7.2. O herbicida paraquat promoveu os melhores indices de germinação e vigor de sementes de soja quando utilizado nos estádios R6 e R7.2. Foi possivel antecipar a colheita em relação às plantas não dessecadas por um a seis dias, variando conforme o herbicida e o estádio fenológico em que a dessecação foi realizada.

\section{LITERATURA CITADA}

BRACCINI, A. L. et al. Semeadura da soja no período de safrinha: potencial fisiológico e sanidade das sementes.

R. Bras. Sementes, v. 25, n. 1, p. 76-86, 2003.

BRASIL. Ministério da Agricultura, Pecuária e Abastecimento. Regras para Análise de Sementes. Brasília: MAPA/ACS, 399p. 2009.

DALTRO, E. M. F. Aplicação de dessecantes em pré-colheita: efeito na qualidade fisiológica de sementes de soja. R. Bras. Sementes, v. 32, n. 1, p. 111-122, 2010.

DURIGAN, J. C.; DURIGAN, J. F.; CARVALHO, N. M. Aplicação em pré-colheita de dessecante em duas cultivares de soja (Glicyne max (L.) Merril): III- Efeito sobre a composição química (proteína, óleo e cinzas) e resíduos nas sementes. Planta Daninha, v. 16, n. 3, p. 122-126, 1980.

EMPRESA BRASILEIRA DE PESQUISA AGROPECUÁRIA - EMBRAPA. Centro Nacional de Pesquisa de Soja. Tecnologia de produção de semente Paraná - 2003. Londrina: Embrapa Soja, 2002. p. 134.
EMPRESA BRASILEIRA DE PESQUISAAGROPECUÁRIA - EMBRAPA. Centro Nacional de Pesquisa de Soja. (CNPSo).

Tecnologia de Produção de semente - Paraná - 2004.

Londrina: Embrapa Soja, 2003. p. 218

EMPRESA BRASILEIRA DE PESQUISA

AGROPECUÁRIA - EMBRAPA. Sistema brasileiro de classificação de solos. Brasília: Embrapa Solos, 1999. 412 p

INOUE, M. H. et al. Rendimento de grãos e qualidade de sementes de soja após a aplicação de herbicidas dessecantes. Ci. Rural, v. 33, n. 4, p. 769-770, 2003.

KAPPES, C.; CARVALHO, M. A. C.; YAMASHITA, O. M. Potencial fisiológico de sementes de soja dessecadas com diquat e paraquat. Sci. Agr., v. 10, n. 1, p. 1-6, 2009.

LACERDA, A. L. S. et al. Aplicação de dessecantes na cultura da soja: antecipação da colheita e produção de sementes.

Planta Daninha, v. 19, n. 3, p. 381-390, 2001.

LACERDA, A. L. S. et al. Armazenamento de sementes de soja dessecadas e avaliação da qualidade fisiológica, bioquímica e sanitária. R. Bras. Sementes, v. 25, n. 2, p. $97-105,2003$.

LACERDA, A. L. S. et al. Efeitos da dessecação de plantas de soja no potencial fisiológico e sanitário das sementes. Tecnologia de sementes. Bragantia, v. 64, n. 3, p. 447-457, 2005.

NAKASHIMA, E. K. et al. Dessecação química na obtenção de sementes de soja de elevada qualidade fisiológica.

R. Ceres, v. 47, n. 273, p. 483-493, 2000.

PELÚZIO, J. M. et al. Influência da dessecação química e retardamento de colheita na qualidade fisiológica de sementes de soja no sul do Estado do Tocantins. Biosci. J., v. 24, n. 2 , p. $77-82,2008$.

RATNAYAKE, S.; SHAW, D. R. Effects of harvest-aid herbicides on soybean (Glycine max) seed yield and quality. Weed Technol., v. 6, n. 2, p. 339-344, 1992

ROMAN, E. S. et al. Dessecação, uma tecnologia que reduz perdas na cultura da soja. Passo Fundo: Embrapa trigo, 2001. $3 \mathrm{p}$.

SANTOS, C. M. et al. Efeitos da aplicação de dessecantes na produção e qualidade das sementes de soja em Uberlândia MG. R. Bras. Herbic., v. 1, n. 1, p. 27-32, 2000.

TERASAWA, J. M. et al. Antecipação da colheita na qualidade fisiológica de sementes de soja. Bragantia, v. 68, n. 3 , p. $765-773,2009$.

VEIGA, A. D. et al. Tolerância de semente de soja a dessecação. Ci. Agrotecnol., v. 31, n. 3, p. 773-780, 2007. 